\title{
Heterosis and the lack of coadaptation in Drosophila nasuta
}

\author{
A. KUMAR \& J. P. GUPTA* \\ Department of Bjological Sciences, University of Notre Dame, Notre Dame, IN 46556, USA and *Department of \\ Zoology, Banaras Hindu University, Varanasi, UP 221005, India
}

\begin{abstract}
Natural populations of Drosophila nasuta are polymorphic for several paracentric inversions. Two non-overlapping inversions on the third chromosome (III-2 and III-35) are heterotic in both laboratory and natural populations and display an extreme case of linkage disequilibrium. Intraand interpopulation crosses involving standard and inverted gene orders of the III-2 and III-35 inversions were made to test if the polygenic complexes within these inversions are coadapted. The inversion heterozygotes formed by the two chromosomes derived from different localities exhibited heterosis since the viability of the heterozygotes was greater than that of either of the two homozygotes. In intrapopulation crosses, the heterozygotes were also heterotic. The present results thus indicated a lack of coadaptation among polygenic complexes within the inversions of $D$. nasuta. The data suggest that the heterosis produced by these linked inversions is the result of natural selection and epistasis.
\end{abstract}

Keywords: coadaptation, Drosophila nasuta, heterosis, inversions, populations.

\section{Introduction}

Natural populations of many species of Drosophila are polymorphic for a variety of chromosomal aberrations. Among them, paracentric inversions are most common. Studies in natural as well as in laboratory populations have shown that the paracentric inversions are heterotic in the heterozygous state (Sperlich \& Pfriem, 1986). The heterotic property of inversions is supposed to be due to complexes of genes which they hold together and prevent from breaking-up through recombination (da Cunha, 1955).

Using intra- and interpopulation crosses in Drosophila pseudoobscura, Dobzhansky and co-workers (for references see Hedrick et al., 1967; Krimbas \& Loukas, 1967; Wallace, 1968; Sperlich \& Pfriem, 1986) have shown that inversion heterozygotes, provided that the two chromosomes are derived from the same locality, are superior in adaptive value to either of the homozygotes. However, the adaptive superiority of inversion heterozygotes is lost in the $F_{2}$ generation when the two chromosomes come from different localities. In such experimental populations, one of the homozygotes always exceeded the heterozygote in fitness. Dobzhansky (1950) suggested that the

Correspondence: Dr A. Kumar, Department of Biological Sciences, University of Notre Dame, Notre Dame, IN 46556, USA. gene arrangements within the inversion are uniquely adapted for a specific locality and are mutually adjusted. This mutual adjustment of gene complexes within the same population to give high heterozygote fitness was called 'coadaptation' (Dobzhansky, 1950).

Drosophila nasuta is a member of the immigrans species group (Wilson et al., 1969) and was first described by Lamb (1914) from the Seychelles Islands in the Indian Ocean. The species has a patchy distribution and has been reported from several countries: India, Sri Lanka, Seychelles Islands, Mauritius, Madagascar, Reunion Islands and Kenya (Kitagawa et al., 1982). In India, the species distribution is also patchy and can be collected only in the winter (i.e. from early November to late March) for a few hours in the morning and the evening when the temperature is much lower. The species is found in the semi-wild areas and has not been found in houses or fruit storage depots. Cytologically, the species displays 85 paracentric inversions, one pericentric inversion and three chromatin band deletions in its natural populations across the distribution range (Kumar \& Gupta, 1986b). In north India, 22 inversions were detected (Kumar \& Gupta, 1986b, c, 1988a), and of these, two inversions (III-2 and III-35) on the third chromosome and one (IIL-2) on the left arm of chromosome 2 were coexisting with the species. The remaining ones were detected 
in a single or a few populations. Inversions III-2, III-35 and IIL-2 are heterotic in both natural and laboratory populations (Kumar \& Gupta, 1989). Moreover, an extreme case of linkage disequilibrium between the III-2 and III-35 inversions has also been described; individuals heterozygous for one inversion and homozygous for the other are rarely observed in natural and laboratory populations (Kumar \& Gupta, 1986a, $1988 \mathrm{~b}$, d). In order to test whether polygenic complexes within the III- 2 and III-35 inversions are coadapted, intra- and interpopulation crosses involving homozygous strains for inverted and standard gene orders were carried out to estimate the relative viability of double homozygotes and double heterozygotes in the $\mathrm{F}_{2}$ generation.

\section{Materials and methods}

Four geographic strains from north India were employed in the present study: Jaunpur (JNP), Ayurvedic Garden (AYG) (Banaras Hindu University Campus), Ramanagar (RNG) and Allahabad (ALD). The distances between Ramanagar and Allahabad, Ramanagar and Jaunpur, and Jaunpur and Allahabad are 140,75 and $100 \mathrm{~km}$, respectively. Ramanagar and Ayurvedic Garden are situated on opposite sides of the river Ganges about $4 \mathrm{~km}$ apart. Naturally inseminated females were collected as described by Kumar \& Gupta (1988a) and were used to initiate isofemale lines. Two isofemale lines heterozygous for both the III-2 and III-35 inversions were randomly selected from each strain. Crosses involving $F_{1}$ individuals from these lines and the St.St/St.St laboratory stock revealed that these isofemale lines had only St.St and MI-2.III-35 chromosome types. One pure line was a double standard homozygote (St.St/St.St) and the other was a double inversion homozygote (III-2.III-35/III-2.III-35). Four interpopulation crosses, between distantly located strains, were made (see Table 1); four intrapopulation crosses served as controls. A one-generation test (Wallace, 1968) was carried out as described by Singh (1972, 1985). Flies homozygous for the standard gene order from one locality and the inverted gene order from another locality (interpopulation crosses) or from the same locality (intrapopulation crosses) were crossed to produce $F_{1}$ offspring. These were mated among themselves to produce $F_{2}$ offspring. For each cross, nearly $100 \mathrm{~F}_{2}$ larvae were examined for their karyotype using polytene chromosome squash preparations stained with lacto-aceto-Orcein. The relative viability, chi-square and variance were calculated as described by Dobzhansky \& Levene (1951).

\section{Results}

When flies homozygous for the standard and inverted gene orders were crossed to produce $F_{1}$ offspring, which were crossed amongst themselves to produce $F_{2}$ offspring, 50 per cent of the eggs deposited are expected to be inversion heterozygotes, 25 per cent homozygotes for standard sequence, and 25 per cent homozygotes for inverted gene orders. However, due

Table 1 Frequencies and relative viabilities of the homozygotes and heterozygotes for the III-2.III-35 inversions in the $\mathrm{F}_{2}$ generation of intra- and interpopulation crosses in Drosophila nasuta

\begin{tabular}{|c|c|c|c|c|}
\hline \multirow[b]{2}{*}{ Crosses } & \multirow[b]{2}{*}{$N$} & \multicolumn{3}{|l|}{ Karyotypes } \\
\hline & & St hom & Inv het & Inv hom \\
\hline \multicolumn{5}{|l|}{ Intrapopulation } \\
\hline NNP & $100 n(v)$ & $30\{0.86 \pm 0.20\}$ & $65\langle 1\rangle$ & $5(0.12 \pm 0.07)^{*}$ \\
\hline RNG & $100 n(v)$ & $26(0.72 \pm 0.17)$ & $67(1)$ & $7(0.17 \pm 0.08)^{*}$ \\
\hline AYG & $100 n(v)$ & $20(0.52 \pm 0.14)^{*}$ & $70(1)$ & $10(0.25 \pm 0.09)^{*}$ \\
\hline$A L D$ & $100 n(v)$ & $28(0.76 \pm 0.18)$ & $69(1)$ & $3(0.05 \pm 0.05)^{*}$ \\
\hline \multicolumn{5}{|c|}{ Interpopulation crosses } \\
\hline JNP-St $\times$ RNG-Inv & $100 n(v)$ & $29(0.81 \pm 0.19)$ & $67(1)$ & $4(0.09 \pm 0.05)^{*}$ \\
\hline JNP-Inv $\times$ AYG-St & $104 n(v)$ & $27(0.71 \pm 0.17)$ & $71(1)$ & $6(0.13 \pm 0.07)^{*}$ \\
\hline JNP-St $\times$ ALD-Inv & $98 n(v)$ & $29(0.92 \pm 0.22)$ & $59(1)$ & $10(0.30 \pm 0.11)^{*}$ \\
\hline RNG-Inv $\times$ ALD-St & $112 n(v)$ & $23(0.53 \pm 0.13)^{*}$ & $80(1)$ & $9(0.19 \pm 0.08)^{*}$ \\
\hline
\end{tabular}

Abbreviations: $\mathbf{S t}=$ standard gene order; $I n v=$ inverted gene order; $n=$ observed number; $v=$ viability; $N=$ number of $\mathrm{F}_{2}$ larvae examined; hom $=$ homozygotes; het $=$ heterozygotes.

${ }^{*}$ At $P<0,05$ (d.f. $\left.=1\right)$. 
to differential selection and survival, the initial Mendelian ratio of $1: 2: 1$ is altered. This can be demonstrated by the following results. The relative viability of homozygotes was calculated on the basis of deviation from expected Mendelian ratio in the $F_{2}$ progeny, assuming that the viability of heterozygotes is always one.

Table 1 provides frequencies of homozygotes and heterozygotes in intra- and interpopulation crosses and the relative viabilities of three karyotypes of $D$. nasuta. In all interpopulation crosses, the relative viability of heterozygotes was greater than that of either of the two homozygotes, suggesting superior fitness of heterozygotes over homozygotes. The viability difference between the standard homozygotes and heterozygotes was significant in only one interpopulation cross (i.e. Ramanagar $\times$ Allahabad $)$. The viability difference between the inversion heterozygotes and inversion homozygotes was significant in all interpopulation crosses. The intrapopulation crosses showed a similar pattern of results.

\section{Discussion}

Evidence for selectional coadaptation has previously been shown in a few species of Drosophila, namely, $D$. paulistorim and D. willistoni (Dobzhansky \& Pavlovsky, 1953, 1958), D. pavani (Bimcic, 1961), and D. melanogaster (Wallace, 1955). Wallace $(1953,1959)$ observed that 'triads' of inversions overiapping with each other do not occur at the same locality in $D$. pseudoobscura. Crossing-over does not occur inside inversions when only inversions 1 and 3 coexist in a population; however, the presence of inversion 2 causes disruption of coadapted gene blocks between 1 and 3 heterozygotes. To explain this phenomenon of selectional coadaptation, Dobzhansky and co-workers and Wallace (1953) hypothesized that variant gene arrangements maintained by natural selection in the same locality are likely to be such that the integrity of coadapted gene complexes will be protected by the inversion heterozygotes from breaking-up. However, in the experimental populations of geographically mixed origin, there are chromosomes with identical gene arrangements, but which contain different constellations of alleles because the dissimilarity in their origin decreases the probability that the two alleles at a given locus are identical (see Wallace, 1968). The alleles found at various loci in a given chromosome from a locality are more likely to be identical to those found in a second identical chromosome from the same locality than to those in an identical chromosome from another locality (Wallace, 1968). Crossing-over between such chromosomes yields new gene combinations, not possible in nature because of the geographic isolation of the parental populations. Hedrick et al. (1967) suggested that gene combinations tied together by inversions represent highly selected gametic types that interact favourably within a population but produce unfavourable interactions when brought together from diverse populations.

In contrast to the above studies, McFarquhar \& Robertson (1963) observed a lack of $F_{2}$ breakdown in interpopulation crosses of $D$. subobscura. They suggested that the lack of coadaptation would favour the spread of advantageous genes and gene combinations via immigration from the population in which they arose. $D$. subobscura has rigid chromosomal polymorphism (Krimbas \& Loukas, 1967). Carson (1965) suggested that most of the polymorphisms among the widespread species of Drosophila are rigid, maintained by a process of heteroselection, i.e. selection for a heterozygous genotype. Heteroselection could be explained on the basis of simple luxuriance (Carson, 1959 , 1965) rather than populational heterosis (coadaptation). Heteroselection helps in adjustment of the organism by direct contributions of heterosis to fitness; the organism is heterotically buffered in all niches occupied by the species (Carson, 1959). Recently Singh (1985) has shown the persistence of $F_{2}$ heterosis in most interpopulation crosses involving three cosmopolitan inversions in $D$. antanassae. He suggested that the heterosis associated with cosmopoli$\tan$ inversions in this species is due to simple luxuriance rather than coadaptation. No explanation is given as to why a few interpopulation crosses in $D$. ananassae failed to show $F_{2}$ heterosis (see Singh, 1985). It is possible that such differences are related to the degree of reproductive isolation, breeding structure and differences in habitat between populations (McFarquhar \& Robertson, 1963). Breeding structure is determined chiefly by average effective population size, and some populations may have a stable existence, while others may experience a more unstable existence with recurring low effective population size (McFarquhar \& Robertson, 1963). Population instability may lead to the loss of coadaptation. The present study indicates that $D$. nasuta heterozygotes formed by two chromosomes derived from two localities exhibit heterosis, since the relative viability (a component of fitness) of heterozygotes was always greater than that of the homozygotes. These data therefore provide no evidence of selectional coadaptation among polygenic complexes within the III- 2 and III-35 inversions in $D$. nasuta. As in $D$. subobscura and $D$. ananassae, the heterosis associated with the linked III-2 and III-35 inversions in D. nasuta is also due to simple luxuriance. However, in addition to simple 
Juxuriance, epistatic gene interactions among the polygenic complexes within the III- 2 and III- 35 inversions are also involved (see discussion below). Unlike the earlier studies, crosses were made in the present study between flies homozygous for both the III-2 and III-35 inversions combination since we repeatedly failed to separate these inversions from one another.

Inversions III-2 and III-35 comprise about 7 and 14 per cent of the length of chromosome 3, respectively, and the distance between them is about 25 per cent of the total chromosome length (Kumar \& Gupta, 1988b). Since crossing-over occurs in pseudoalleles, crossingover is expected to occur with a rather high frequency between these two inversions and a state of equilibrium should be maintained in all populations. However, our earlier studies have shown an extreme case of linkage disequilibrium between these inversions with a superiority of double inversion heterozygotes. The degree of linkage disequilibrium (on a scale of 0 to 1 ) is either 1 or close to 1 in all populations. The rate of recombination between these inversions ranges from 1.5 to 5.6 per cent in different strains under laboratory conditions (Kumar \& Gupta, 1988b). This is supported by the low percentage of tecombinants $\{2.74$ per cent $)$ observed in natural populations of this species (Kumar \& Gupta, 1986a). The linkage disequilibrium and the superiority of double inversion heterozygotes persisted even after 32 generations of random mating in six laboratory stocks of different geographic origin which were initiated from single naturally inseminated females heterozygous for the III- 2 and III-35 inversions in coupling association; the recombinants were observed in only two stocks (Kumar \& Gupta, 1988 d). Moreover, the linkage disequilibrium and the superiority of double inversion heterozygotes were also observed during different months in this species (Kumar \& Gupta, 1988c). The scarcity of recombinants suggests that crossover products may be lethal, or at least sublethal, because of intrachromosomal epistatic interaction. Dobzhansky \& Spassky (1960) reported that synthetic lethality as a result of gene interaction is frequent in $D$. pseudoobscura. Fisher (1930) suggested that if the crossing-over rate is genetically determined and if recombinants are less fit, selection tends to reduce recombination between interacting genes and leads to an increase in the fitness of the desired combination of genes.

Inversions contain multiple interacting blocks of genes that are held together and prevented from breaking-up by the suppression of recombination (Dobzhansky, 1970; Wallace, 1968). Selection may favour linked interacting genes that are not part of allelic blocks, and the whole chromosome may be treated as a functional and selective unit (Levitan,
1958; Sperlich \& Feuerbach-Mravlag, 1974). This may be the case for the III-2.III-35 chromosome type in $D$. nasuta. Thus the superiority of double inversion heterozygotes in the $F_{1}$ (data not shown) and $F_{2}$ generations in the present study, in crosses involving two chromosomes coming from different localities, is the result of natural selection and epistatic gene interaction. Natural selection and epistasis suppress recombination not only among polygenic complexes within the III-2 and III-35 inversions but also between these two inversions in order to provide superior fitness to the species in the many environmental condition in which it lives.

\section{Acknowledgements}

We thank Dr L. E. Munstermann for comments on the manuscript. We also thank the reviewer for important suggestions. The senior author is grateful to the Council of Scientific and Industrial Research, Government of India for financial assistance. This work was carried out when the senior author was a doctoral student at the Center of Advanced Study in Zoology, Banaras Hindu University, Varanasi, India.

\section{References}

BIRNCIC. D. 1961. Integration of genotypes in geographic populations of Drosophila pavani. Evolution, 15, 92-97.

da CunHA, A. B. 1955. Chromosomal polymorphism in the Diptera. Adv. Genet., 7, 93-138.

CARSON, H. L. 1959. Genetic conditions which promote or retard the formation of species. Cold Spr. Harb. Symp. Quant. Biol., 24,87-115.

CARSON, H. L. 1965. Chromosomal morphism in geographically widespread species of Drosophila. In: Baker, H. G. and Stebbins, G. L. (eds) The Genetics of Colonizing Species. Academic Press, London, pp. 503-531.

DOBZHANSKY. Th. 1950. Genetics of natural populations. XIX. Origin of heterosis through natural selection in populations of Drosophila pseudoobscura. Genetics, 35 , 288-302.

DOBZHANSKY. Th. 1970. Genetics of the Evolutionary Process. Columbia University Press, New York, pp. 126-164.

DOBZHANSKY, Th. AND LEVENE, H. 1951. Development of heterosis through natural selection in experimental populations of Drosophila pseudoobscura. Am. Nat., 85(823), 247-264.

DOBZHANSKY, Th. AND PAVLOVSKY, o. 1953. The indeterminate outcome of certain experiments on Drosophilo populations. Evolution, 7, 198-210.

DOBZHANSKY, Th. AND PAVLOYSKY, O. 1958. Interracial hybridization and breakdown of coadapted gene complexes in Drosophila paulistorum and Drosophila willistoni. Proc. Nat. Acad. Sci. (USA), 44, 622-629. 
DOBZHANSKY, Th. AND SPASSKY, B. 1960. Release of genetic variability through recombination. V. Breakup of synthetic lethals by crossing over in Drosophila pseudoobscura. Zool. Jahrb., 88, 57-66.

FSHER, R. A. 1930. The Genetical Theory of Natural Selection. Clarendon Press, Oxford, pp. 22-120.

HEDRICK, P., JAIN, S. AND HOLDEN, L, 1967. Multiple systems in evolution. In: Hecht, M. K., Steere, W. C. and Wallace, B. (eds) Evolutionary Biology. Plenum Press, New York, vol. 11, pp. 104-173.

KITAGAWA, O., WAKAHAMA, K. J., FUYAMA, Y., SHIMADA, T., TAKANASI, E., HATSLMMI, M., UWABO, M. AND MITA, Y. 1982. Genetic studies of the Drosophila nasuta subgroup, with notes on the distribution and morphology. Jap. J. Genet., 57, 113-141.

KRIMBAS, C. B. AND LOUKAS, M. 1967. The inversion polymorphism of Drosophita subobscura. In; Hecht, M. K., Steere, W. C. and Wallace, B. (eds) Evolutionary Biology. Plenum Press, New York, vol. 12, pp. 163-228.

KUMAR, A. AND GUPTA, J. P. 1986a. Linkage disequilibrium between two naturally occurring gene arrangements of Drosophila nasuta. Heredity, 57, 1-4.

KUMAR, A. AND GUPTA, J. P. 1986 b. Inversion polymorphism in Drosophila nasuta. Dros. Inf. Ser., 63, 78-80.

KUMAR, A. AND GUPTA, J. P. $1986 \mathrm{c}$. Terminal chromatin band deletions in the polytene chromosomes of Drosophila nasuta. Braz, J. Genet., 9(3), 539-543.

KUMAR, A. AND GUPTA, J. P. $1988 \mathrm{a}$. Genetics of natural populations of Drosophila nasuta. J. Hered., 79, 83-88.

KUMAR, A. AND GUPTA, J. P. 1988b. Linkage disequilibrium, natural selection, and epistatic gene interactions in Drosophila nasuta. Genome, 30, 495-498.

KUMAR, A. AND GUPTA, J. P. 1988c. Temporal variation and gametic disequilibrium in Drosophila nasuta. Hereditas, 109, 113-117.

KUMAR, A. AND GUPTA, J. P. 1988d. Linkage disequilibrium in laboratory populations of Drosophila nasuta. Theor. Appl. Genet., 75, 902-904.

KUMAR, A. AND GUPTA, J. P. 1989. Gene frequencies in natural and laboratory populations of Drosophila nasuta. Hereditas, 110, 1-5.

LAMB, C. G. 1914. Diptera: Heteroneuridae, Ortalidae, Milichidae of the Seychelles. Trans. Linn. Soc. London, $16,307-372$.

LEVITAN, M. 1958. Non-random associations of inversions. Cold Spr. Harb. Symp. Quant. Biol., 23, 251-268.

MCFAROUHAR, A. M. AND ROBERTSON, F. W. 1963. The lack of evidence for coadaptation in crosses between geographical races of Drosophila subobscura coll. Genet. Res., 4, 104-131.

SINGH, в. N. 1972. The lack of evidence for coadaptation in crosses between geographic populations of Drosophila ananassae. Genetica, 43, 582-588.

SINGH, B. N. 1985. Heterosis without selectional coadaptation in Drosophila ananassae. Theor. Appt. Genet., 69, 437-441.

SPERLICH, D. AND FEUERBACH-MRAVLAG, H. 1974. Epistatic gene interaction, crossing over and linked and unlinked inversions in Drosophila subobscura. Evolution, 28, 67-75.

SPERLICH, D. AND PFRIEM, P. 1986. Chromosomal polymorphism in natural and experimental populations. In: Ashburner, M., Carson, H. L. and Thompson Jr, J. N. (eds) The Genetics and Biology of Drosophila. Academic Press, vol. 3e, pp. 257-293.

wallace, B. 1953. On coadaptation in Drosophila. Am. Nat., 87, 343-358.

WALLACE, 8. 1955. Interpopulation hybrids in Drosophila melanogaster. Evolution, 9, 302-316.

WALLACE, B. 1959. Influence of genetic systems on the geographic distribution. Cold Spr. Harb. Symp. Quant. Biol., 24, 193-204.

WALLACE, B. 1968. Topics in Population Genetics. W. W. Norton and Company, New York, pp. 305-320.

WILSON, F. D., WHEELER, M. R., HARGET, M. AND KAMBYSELLIS, M. 1969. Cytogenetic relations in the Drosophila nasuta subgroup of the immigrans group of species. Studies in Genetics (Univ. Texas Publ), 6918, 207-253. 